\title{
Application of Recycled Coarse Aggregate in Steel Tubular Members
}

\author{
Gajalakshmi Pandulu†, Revathy Jayaseelan and Mohana Priya \\ Department of Civil Engineering, B. S. Abdur Rahman Crescent Institute of Science \& Technology, Chennai, \\ Tamil Nadu, India \\ †Corresponding author: Gajalakshmi Pandulu; gajalakshmi@crescent.education
}

\section{Nat. Env. \& Poll. Tech.} Website: www.neptjournal.com

Received: 18-07-2019

Accepted: 29-08-2019

\section{Key Words:}

Demolition waste;

Recycled coarse

aggregate; Concrete

filled steel tubes; Taguchi approach

\begin{abstract}
Recycled aggregate from the demolition of buildings provides a sustainable solution in reducing the space required for dumping demolished waste as landfill and also reduces the consumption of natural aggregate. A percentage of recycled coarse aggregate can be used in structural members which can be economical and environmentally useful. This experimental study consists of three phases. In Phase I, an attempt was made to use Recycled Coarse Aggregate (RCA) in place of Natural Coarse Aggregate(NCA) in concrete. Experimental results of concrete for various combinations of RCA with NCA wereanalysed numerically for the optimum value using Taguchi's method. In Phase II, the confirmation study was conducted to study the strength and durability characteristics of concrete made with the optimized value of recycled aggregate. In Phase III, the application of optimized recycled coarse aggregate concrete was done by conducting a study on the load-carrying capacity of recycled coarse aggregate concrete-filled steel tube members. The results revealed that there is a marginal increase in load-carrying capacity of recycled coarse aggregate concrete-filled steel tube members than natural coarse aggregate concrete-filled steel tube members. This application proves to be ecofriendly and environmentally sustainable by using the demolished concrete in the structural member.
\end{abstract}

\section{INTRODUCTION}

Concrete is a man-made product which consists of large chunks of cement, coarse and fine aggregate mixed with water and/or admixture. Concrete is the most widely used construction material across the world in all types of construction. In a concrete mixture, aggregate occupies the major part. In conventional construction, coarse aggregate from quarries and sand from river beds play a vital role. The availability of these natural sources is decreasing at a larger scale due to overconsumption and increased development in the field of construction (Tiwari 2015, Chakradhara Rao 2011). The supply of the aggregates has emerged as a major problem in many cities across India. For this purpose, recycling of demolition waste is gaining importance (Matias 2013, Vieira 2016). Also,beams cast with RCA rather experienced greater deflections under a service load and smaller cracking moments (Ganesh 2014). The recycled coarse aggregate can be used only after reducing it to the normal size and standards. While universally accepting the need to promote the use of RCA in the wider application, it must be remembered that the aggregate for the concrete application must adhere to the requirements set in the relevant specification for its intended use (Kazuhisa 2014, Alexandre Bogas 2014). The effect of recycled aggregate must be assessed and worked out for the optimum percentage to produce a concrete of good quality.
In the case of composite construction, the concrete and steel are coupled in such a manner that the advantages of both the materials are utilized effectively in composite members. Concrete-filled steel tubular (CFT) members have evolved to become popular structural members used in buildings, bridges etc., due to their outstanding structural performance characteristics such as high strength, high ductility, savings in formwork, smaller cross-section over reinforced concrete structures and high fire resistance over the steel structures (Gajalakshmi 2011). RCA filled stainless steel tube stub columns and beams under short-term loadings exhibit stable load versus deformation responses and the performance of core RAC was usually enhanced to the appreciable extent due to the confinement of the outer stainless steel tube (Wang 2015, YouFu 2006, Youfu 2013). The variation in compressive strength for the columns filled with RCA is noticeable (Vivian 2016, Kou 2012). In this study, an attempt is made to study the performance of CFT members filled concrete prepared by partially replacing NCA with RCA. This application renders to maintain a sustainable environment.

\section{MATERIALS AND METHODS}

\section{Phase I - Experimental Study on Materials}

In Phase I, an experimental study was conducted on testing of material properties, development of mix design for M25 
and M35 grade concrete and testing of hardened properties such as compressive and split tensile strength. The optimum value of RCA has been found out by Taguchi's approach by using these experimental results in Phase I.

Material properties: The physical properties of natural coarse aggregate and recycled coarse aggregate are compared and are given in Table 1. The cement of grade OPC 53 is used for testing. The concrete mix was designed for the cube compressive strength of $25 \mathrm{MPa}$ and $35 \mathrm{MPa}$ at 28 days with mix ratios of 1:1.37:2.6 @ 0.45 w/c ratio and 1:1.8:2.7@ $0.5 \mathrm{w} / \mathrm{c}$ ratio respectively with $12.5 \mathrm{~mm}(\max )$ size of natural and recycled coarse aggregate and $2.36 \mathrm{~mm}(\mathrm{max})$ size fine aggregate based on ACI committee 211.1.1991 recommendations. From the concrete mixes, cubes and cylinders were cast for various percentages of recycled coarse aggregate (RCA) $(40 \%, 60 \%, 80 \%$, and $100 \%)$ with and without admixture (modified polycarboxylic ether) and were tested to obtain the optimum percentage of RCA using Taguchi method.

Taguchi's approach- Analysis of results of compressive and tensile strength: Taguchi (1986) (Ganesan, 2011) developed a method based on orthogonal array for designing experiments to investigate how different factors affect the response especially the mean and variance. Taguchi has coupled design of experiments with optimization of control factors to ensure the best optimal results. He also introduced the concept of signal to noise ratio $(\mathrm{S} / \mathrm{N})$, where the signal is the mean response and noise is variation due to uncontrolled

Table 1: Physical properties of Aggregates.

\begin{tabular}{|lll|}
\hline Physical properties & Water absorption $(\%)$ & Specific gravity \\
\hline NCA & 1.48 & 2.68 \\
RCA & 5.8 & 2.2 \\
$\begin{array}{l}\text { Fine Aggregate } \\
\text { (Zone II) }\end{array}$ & - & 2.65 \\
\hline
\end{tabular}

factors. The signal to noise ratio is nothing but log functions of desired response and also serve as an objective function for optimization in experimental data analysis. Taguchi has tabulated 18 basic orthogonal arrays called 'Standard Orthogonal Array'. The process of fitting an orthogonal array to a specific experimental study has been made easy by employing one of the standard orthogonal arrays. The average $\mathrm{S} / \mathrm{N}$ ratio for each factor and levels were calculated. Keeping in mind the objective of the experiment, viz., maximization or minimization of the performance measure, the best level for each factor can be selected and as per Taguchi's approach $\mathrm{S} / \mathrm{N}$ ratio is given by-

$$
\mathrm{S} / \mathrm{N} \text { ratio }=-10 \log \left[\frac{1}{N} \sum Y_{i}^{2}\right]
$$

where $\mathrm{N}$ is the number of experiments and $\mathrm{Y}_{\mathrm{i}}$ is the mean of all the experiments.

\section{Analysis of Results Using the Taguchi Approach}

Based on Taguchi method, the suitable array for the compressive test results selected for the analysis is $4^{2}$ (L8), where 4 represents the factors and 2 represents the levels which are shown in Table 2 with four factors as percentage replacement of natural coarse aggregate with recycled coarse aggregate (A1-40\%, A2-60\%, A3-80\% and A4-100\%) and two levels of different grades (C1-M25 and C2-M35) and admixtures (B1-0\% and $\mathrm{B} 2-0.6 \%$ ). The $\mathrm{S} / \mathrm{N}$ ratios were calculated for both compressive strength and tensile strength as shown in

Table 2: Array table.

\begin{tabular}{|lllll|}
\hline & \multicolumn{3}{c}{ C1 } & \multicolumn{2}{c|}{ C2 } \\
\cline { 2 - 5 } & B1 & B2 & B1 & B2 \\
\hline A1 & 33.35 & 40.4 & 38.66 & 45.42 \\
A2 & 34.51 & 38.73 & 38.27 & 43.37 \\
A3 & 29.24 & 34.78 & 35.36 & 38.97 \\
A4 & 28.80 & 29.07 & 30.76 & 33.16 \\
\hline
\end{tabular}

Table 3: $\mathrm{S} / \mathrm{N}$ ratio of compressive strength of cube.

\begin{tabular}{|c|c|c|c|c|c|}
\hline \multirow[t]{2}{*}{$\%$ of Replacement } & \multirow[t]{2}{*}{$\%$ of Admixture } & \multicolumn{2}{|c|}{ Compressive strength results $\left(\mathrm{N} / \mathrm{mm}^{2}\right)$} & \multicolumn{2}{|c|}{$\mathrm{S} / \mathrm{N}$ ratio } \\
\hline & & M25 & M35 & M25 & M35 \\
\hline 0 & 0 & 24.4 & 35.16 & 27.75 & 30.92 \\
\hline 0 & 0.6 & 27.42 & 40.13 & 28.76 & 32.06 \\
\hline 40 & 0 & 33.35 & 38.66 & 30.46 & 31.75 \\
\hline 40 & 0.6 & 40.4 & 45.42 & 32.12 & 33.14 \\
\hline 60 & 0 & 31.57 & 38.27 & 31.66 & 31.66 \\
\hline 60 & 0.6 & 38.73 & 43.37 & 31.76 & 32.14 \\
\hline 80 & 0 & 29.24 & 35.36 & 29.32 & 30.97 \\
\hline 80 & 0.6 & 34.78 & 38.97 & 30.83 & 31.81 \\
\hline 100 & 0 & 28.8 & 30.76 & 29.19 & 29.75 \\
\hline 100 & 0.6 & 29.07 & 33.16 & 29.27 & 30.41 \\
\hline
\end{tabular}


Tables 3 and 4 . The $40 \%$ replacement of RCA for NCA has shown improved strength in both compressive and split tensile strength. Hence the optimum value of RCA mixed with NCA is $40 \%$ and $0.6 \%$ admixture which in turn is applied in the casting and testing of structural members. These members, which were cast for this optimum value,were compared with the control member of M35 grade with $0 \%$ RCA and $0.6 \%$ admixture.

\section{RESULTS AND DISCUSSION}

\section{Phase II - (Confirmation Test)}

In Phase II, the confirmation test has been done by studying the strength and durability performance of M25 and M35 grade concrete made with the optimum percentage of RCA and admixture determined by Taguchi's approach.

\section{Strength Performance}

From the Figs. 1 and 2, maximum strength was obtained for the grade M35 with $40 \%$ replacement of natural aggregate with recycled concrete aggregate and $0.6 \%$ of admixture. It is observed to be an $11 \%$ increase when compared with conventional concrete cubes. From the split tensile strength test results, maximum strength was obtained for the grade M35 with $40 \%$ replacement of natural aggregate with recycled concrete aggregate and $0.6 \%$ of admixture. It was observed

Table 4: S/N ratio of the tensile strength of cylinder.

\begin{tabular}{|c|c|c|c|c|c|}
\hline \multirow[t]{2}{*}{$\%$ of Replacement } & \multirow[t]{2}{*}{$\%$ of Admixture } & \multicolumn{2}{|c|}{ Tensile strength results $\left(\mathrm{N} / \mathrm{mm}^{2}\right)$} & \multicolumn{2}{|c|}{$\mathrm{S} / \mathrm{N}$ ratio } \\
\hline & & M25 & M35 & M25 & M35 \\
\hline 0 & 0 & 2.70 & 2.99 & 8.63 & 9.513 \\
\hline 0 & 0.6 & 2.82 & 3.05 & 9.00 & 9.69 \\
\hline 40 & 0 & 2.85 & 2.99 & 9.09 & 9.513 \\
\hline 40 & 0.6 & 2.96 & 3.19 & 9.43 & 10.08 \\
\hline 60 & 0 & 2.72 & 2.81 & 8.69 & 8.97 \\
\hline 60 & 0.6 & 2.80 & 2.91 & 8.94 & 9.28 \\
\hline 80 & 0 & 2.70 & 2.64 & 8.63 & 8.43 \\
\hline 80 & 0.6 & 2.85 & 2.82 & 9.09 & 9.00 \\
\hline 100 & 0 & 2.56 & 2.84 & 8.16 & 9.07 \\
\hline 100 & 0.6 & 2.71 & 2.99 & 8.63 & 9.51 \\
\hline
\end{tabular}

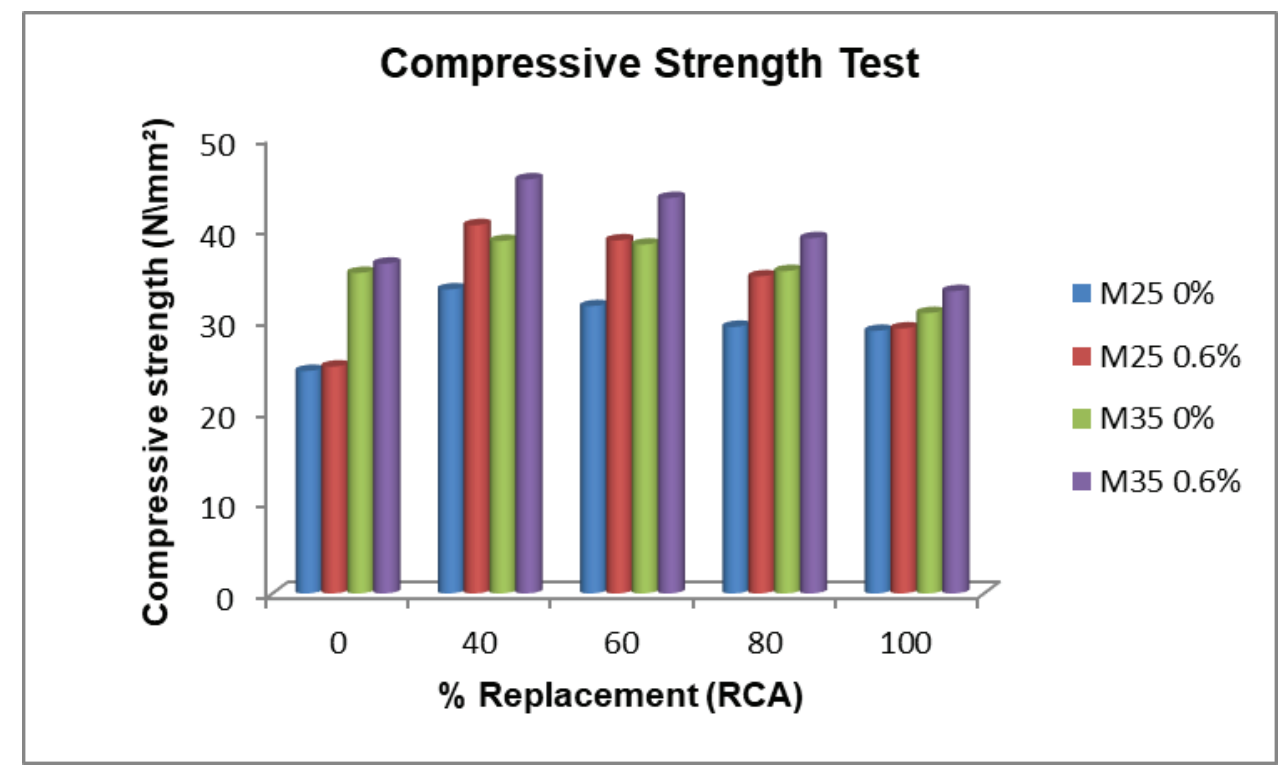

Fig. 1: Compressive strength test results. 


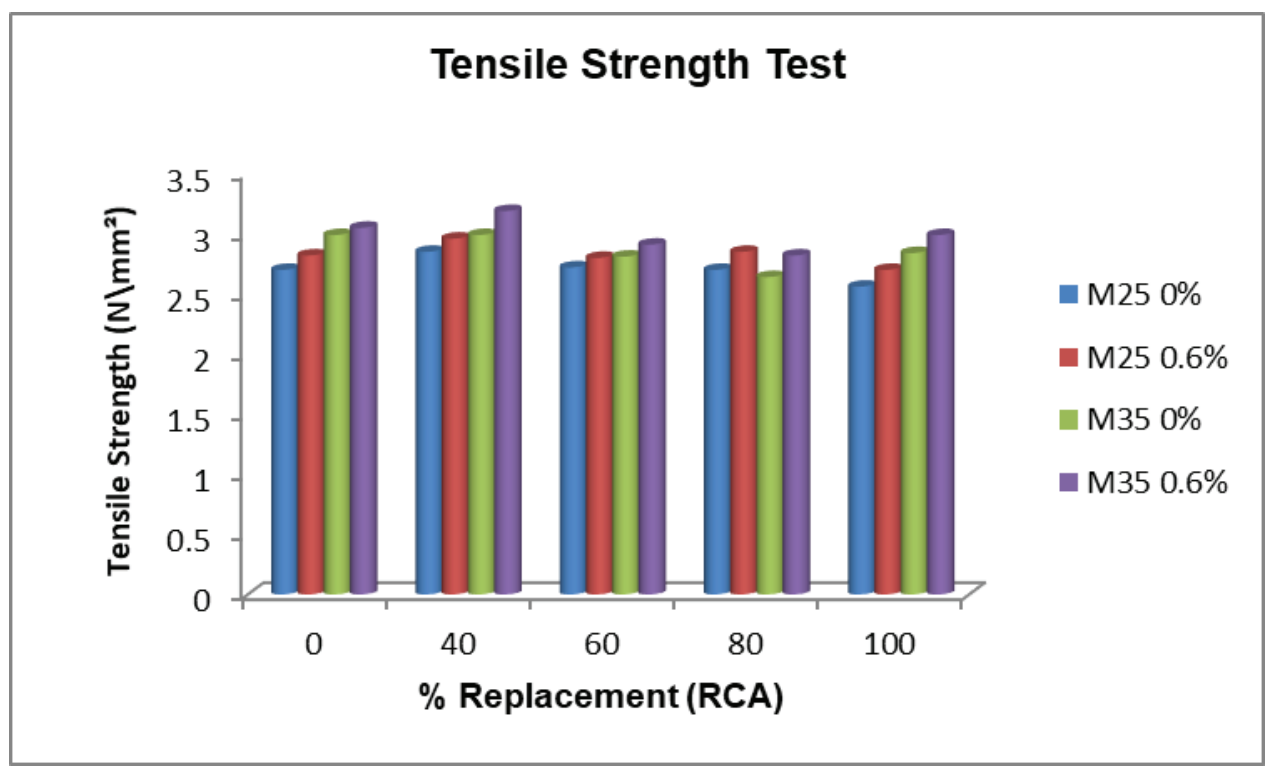

Fig. 2: Tensile strength Test results.

to be a $7.2 \%$ increase when compared with the conventional concrete cylinders.

\section{Durability Performance (Confirmation Test)}

Rapid chloride penetration: The Rapid Chloride Penetration Test (RCPT) is conducted using the cells and the values are recorded for 6 hours at 30 minutes interval with $\mathrm{NaOH}$ and $\mathrm{NaCl}$ on either side of the cell for the specimen of $100 \mathrm{~mm}$ diameter and 50mm height. The specimen is kept in the testing apparatus where one end of the specimen is exposed to sodium chloride and the other end is exposed to sodium
hydroxide.A constant potential voltage of $60 \mathrm{~V}$ was applied across the specimens. The current across the specimen was measured every 30 minutes for the complete 6 -hour test. The total charge passing through the specimen was calculated in coulombs.Higher the value, higher is the permeability. The chloride ion penetrations are measure in terms of the current passed through the specimen. The current passage will be more if the resistance offered by the specimen is less. Based on the test results given in Fig. 3, the chloride penetrating rate is "Moderate" as per ASTM C1202for all grades of concrete with natural coarse aggregate and recycled concrete aggregate.

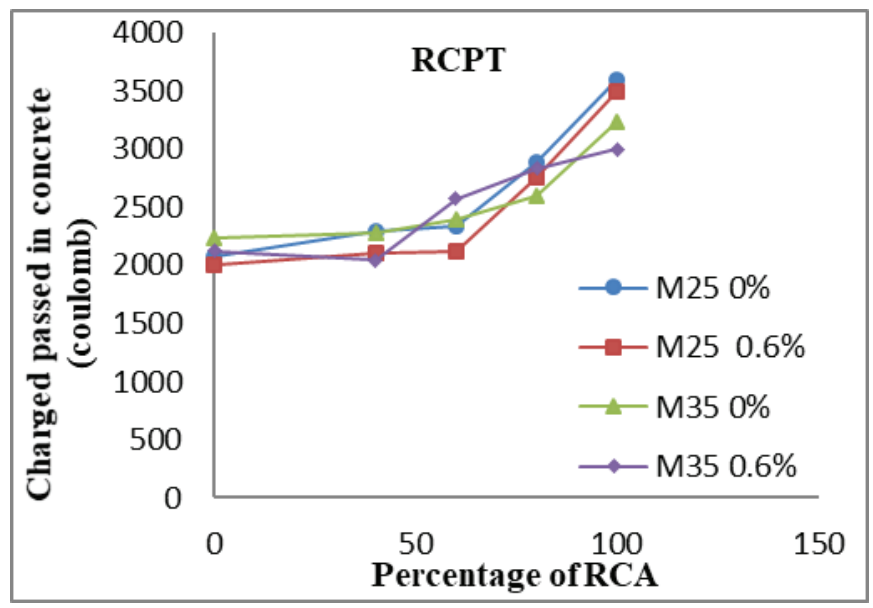

Fig. 3: RCPT test results. 
Sorptivity:Sorptivity test is done to measure thecapillary rise absorption rate of concrete. The cylindrical specimen of diameter $100 \mathrm{~mm}$ was cut into pieces of thickness $50 \mathrm{~mm}$. These specimens were kept in an oven at $100^{\circ}$ Celsius for 24 hours. Waterproofing coating needs to be done on the sides of the specimen. Dry weight has to be taken and the specimen is dumped in water for 30 minutes with $5 \mathrm{~mm}$ above the specimen surface. The wet weight of the specimen was measured. From Figs. 4 and 5, RCA 40\% in M25 grade of concrete shows about $33 \%$ and $33.5 \%$ higher sorptivity values without and with admixture respectively. Similarly, in case of M35, it was found to be $33.2 \%$ and $33.7 \%$ higher sorptivity value than RCA $0 \%$. But still, RCA 40\% satisfies the same range requirements as $0 \%$ RCA. Old mortar in RCA increases the sorptivity of the concrete. Sorptivity values increase with the increase of RCA in new concrete.
Correlation evaluation of the results: The correlation expression is developed between the ratio of the compressive strength of concrete with recycled aggregate and percentage of replacement of recycled concrete is shown in Fig. 6. The value of the regression coefficient (R2) and its corresponding linear equation are presented in Fig. 8 . The $\mathrm{R}^{2}$ coefficient is 0.98 , which is greater than 0.85 (Montgomery \& Peck 2015) exhibiting a remarkable correlation between the chosen parameters. The correlation expression can be adopted in the mix design of concrete made with recycled concrete.

\section{Phase III - (Application of RCA in Steel Tube Members)}

The main objective of this work is to utilize the construction and demolitionconcrete waste from which coarse aggregate is extracted for the use of the manufacturing concrete. The

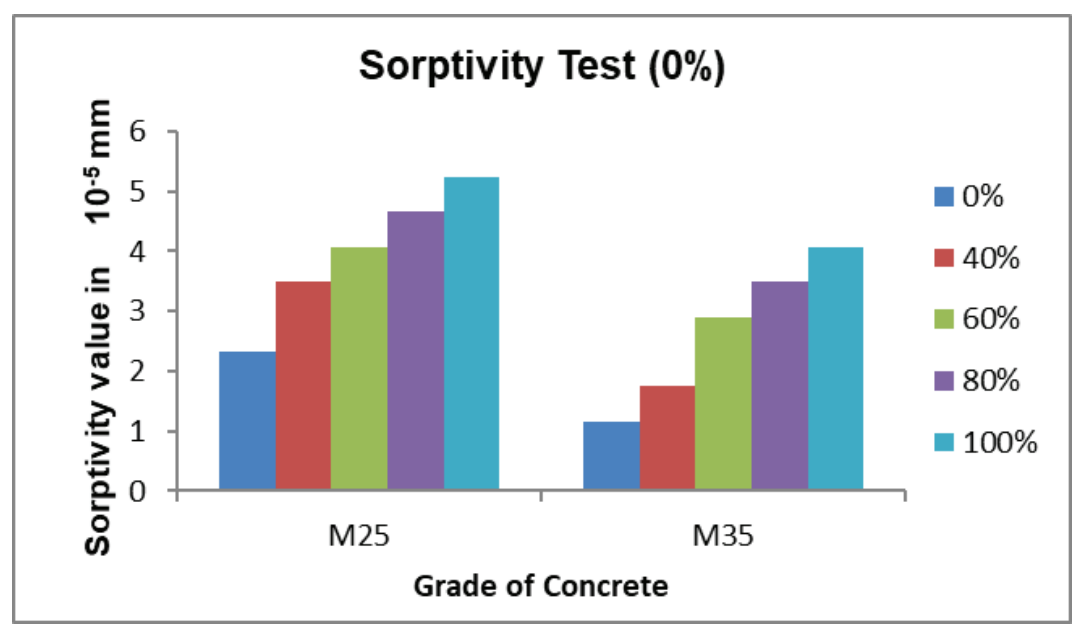

Fig. 4: Sorptivity test results for specimen without admixture.

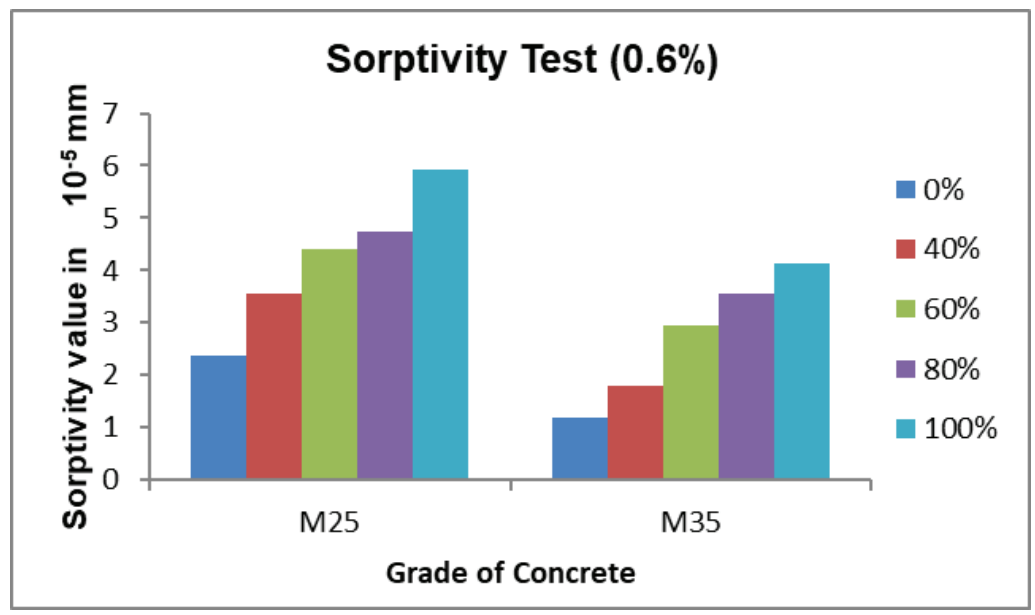

Fig. 5: Sorptivity test results for the specimen with admixture. 


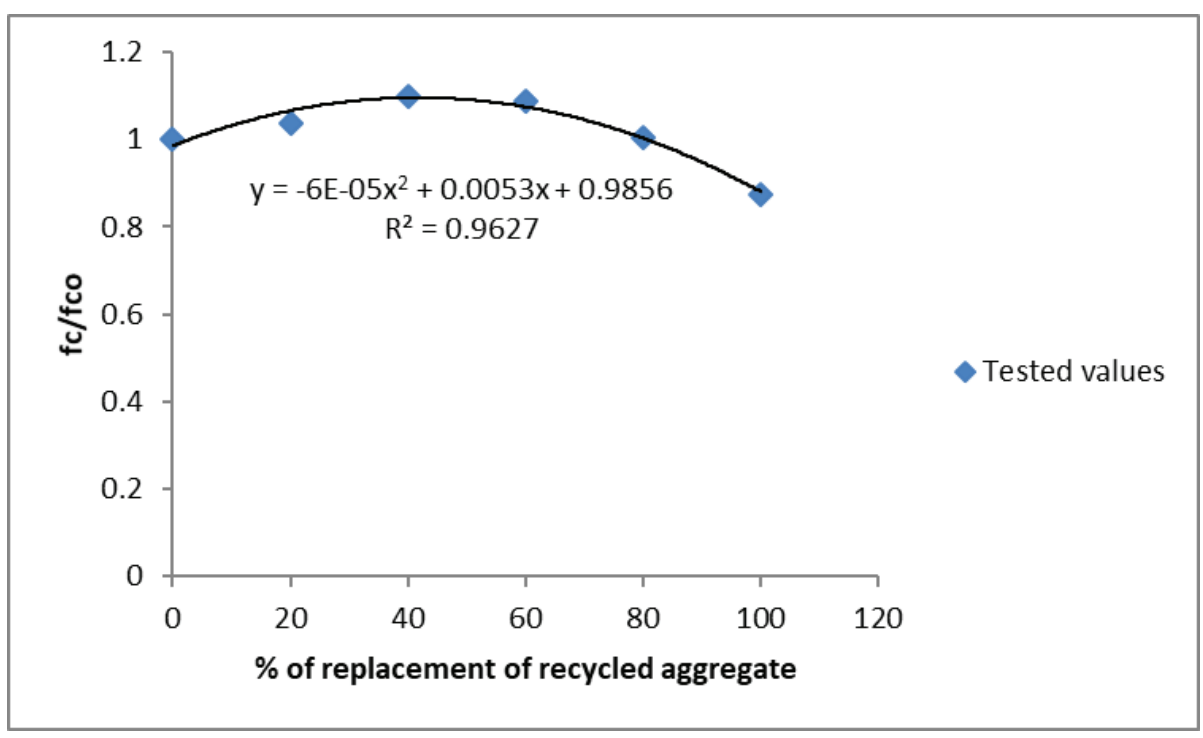

Fig. 6: Correlation evaluation of the results.

optimum percentage of recycled coarse aggregate is obtained from the results of compressive strength and tensile strength tests conducted. The durability of the concrete specimens for the various percentages of RCA in different grades of concrete is observed. In phase III, the experimental program consists of tests on CFT circular columns of diameter $114 \mathrm{~mm}$ and rectangular columns of cross-section $98 \times 48 \mathrm{~mm}$, both members of length $500 \mathrm{~mm}$ with the thickness of the steel tube being $2.5 \mathrm{~mm}$. The CFT circular and rectangular sections of diameter to thickness ratio of 45.6 and 39.2 respectively.
The first part consists of testing of recycled coarse aggregate filled rectangular and circular sections of columns under axial loading. The second part consists of testing of recycled coarse aggregate concrete-filled rectangular beams under two-point loading with simply supported condition. The cross-sections of the beams were $98 \times 48 \mathrm{~mm}$ and the length $1 \mathrm{~m}$. The specimens tested are observed for the maximum load-carrying capacity, axial shortening, strain in column and beam, deflection in beams and failure modes. The specimen labels are given in Table 5.

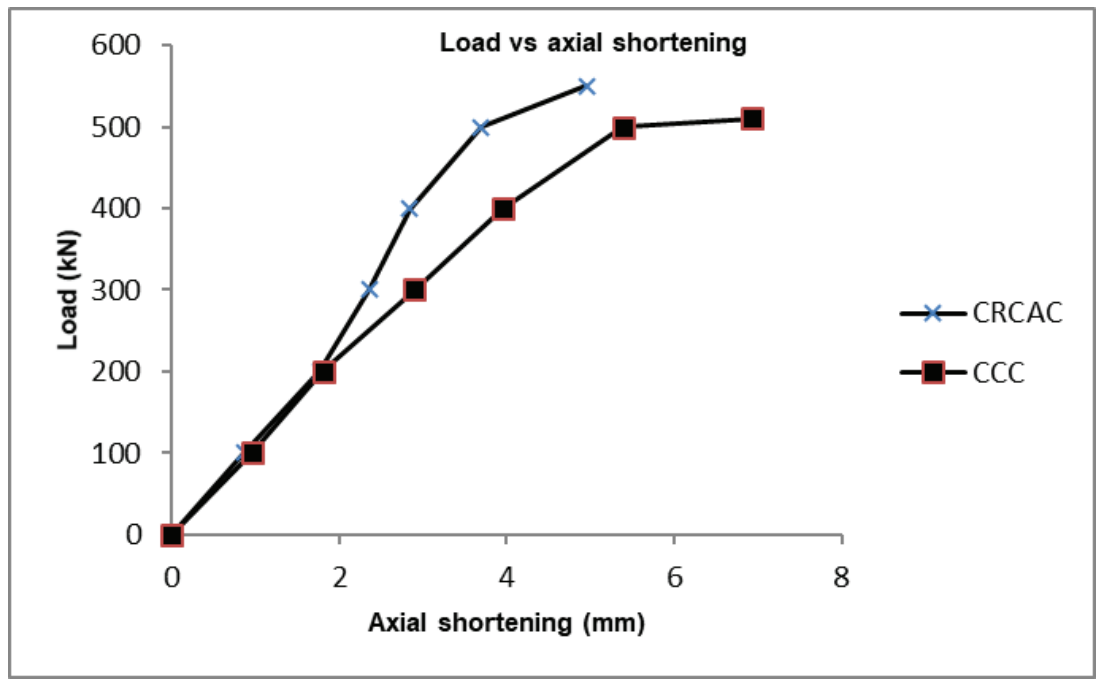

Fig. 7: Load vs axial shortening in the circular column. 


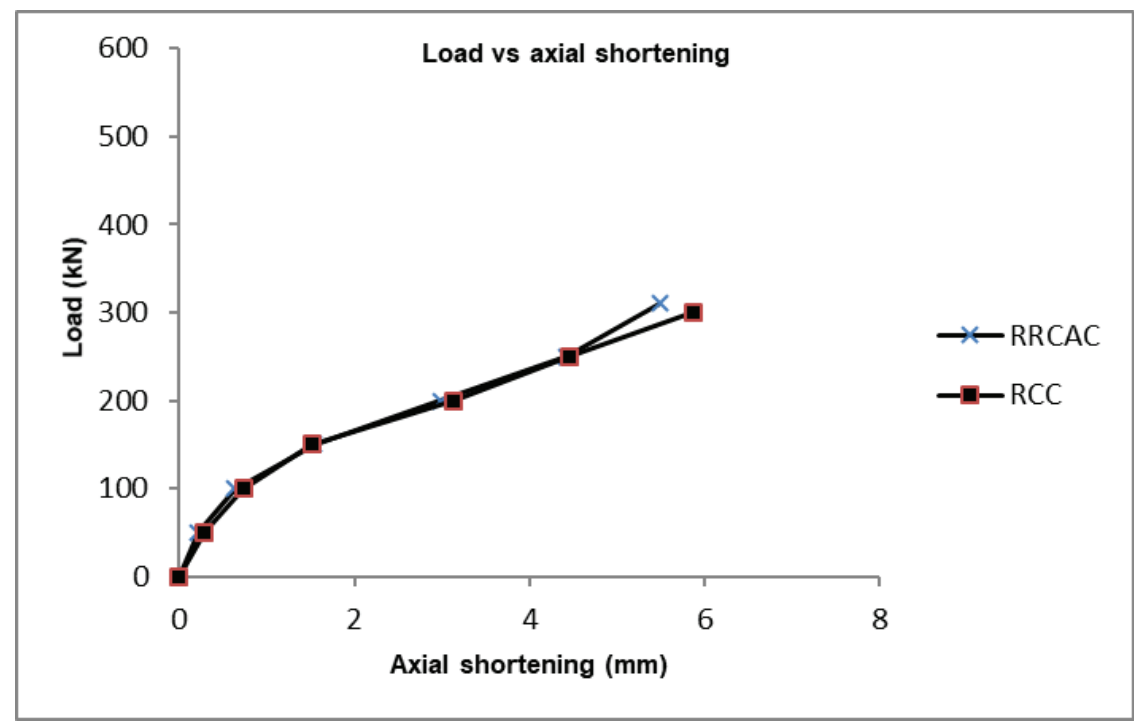

Fig. 8: Load vs axial shortening in rectangular column.

Failure modes and behaviour of RCA concrete-filled steel columns: The test specimens behaved in a ductile manner and testing proceeded in a smooth and controlled fashion. Typical failure modes ofconcretefilled with normal concrete and recycled coarse aggregate concrete were local buckling in columnare shown in Fig. 9. The columns were tested and the crushing of concrete inside the filled tube was heard when $70 \%$ of the load was applied to CCC and $80 \%$ of the load was applied to CRCAC. Similarly, in the case of rectangular columns, the crushing of concrete was observed at $75 \%$ of the load in RCC and $70 \%$ of the load in RRCAC. The buckling in columns occurred at $120 \mathrm{~mm}$ from bottom in both CCC and CRCAC, whereas the buckling occurred at $90 \mathrm{~mm}$ from the top in RCC and $110 \mathrm{~mm}$ from the top in RRCAC. Typical failure modes of columns are shown in Fig. 9. On testing control and RCA concrete in filled columns, the ultimate load carrying capacity of CRCAC was found to be $558 \mathrm{kN}$ which is $7.2 \%$ increase than CCC. The axial shortening of CRCAC and CCC was found to be $6.9 \mathrm{~mm}$ and $4.9 \mathrm{~mm}$ respectively. Similarly, the ultimate load carrying capacity of RRCAC was found to be $308 \mathrm{kN}$ which is $7.2 \%$ lower than RCC and their corresponding axial shortening was found to be $5.5 \mathrm{~mm}$ and $5.8 \mathrm{~mm}$ respectively. The load vs axial shortening of the columns are given in Fig. 7 and Fig. 8. The load carrying capacity of CRCAC has shown $7.2 \%$ increase in comparison with $\mathrm{CCC}$ and RRCAC has shown $3.45 \%$ decrease with RCC. Considering the overall ultimate load carrying capacity, CRCAC has shown an increase of $44.8 \%$ than RRCAC. Similarly, CCC has a $37.8 \%$ increase than RCC which shows that circular columns have higher load carrying capacity than rectangular sections in both control and recycled coarse aggregate concrete infilled column.

Failure modes and behaviour of RCA concrete-filled steel beams: The failure modes of concrete filled with normal concrete and recycled coarse aggregate concrete was bending in beams. The concrete in filled steel beams exhibited bending at the centre with maximum load transferring at the loading points as shown in Fig. 11. When the load was applied, the bottom face of the steel tube exhibited an elongation allowing the beam to bend completely at the ultimate load. RRCAB exhibited a deflection measuring $60 \mathrm{~mm}, 8.3 \%$ greater than $\mathrm{RCB}$. The bending increased with increase in load upto $70 \%$ which is shown in Fig. 10

Table 5: Specimen label for columns and beam.

\begin{tabular}{|llll|}
\hline \multirow{2}{*}{ Specification } & \multicolumn{2}{l|}{ Specimen label for Column } & Specimen label for beam \\
\cline { 2 - 4 } & Circular & Rectangular & Rectangular \\
\hline Control specimen & CCC & RCC & RCB \\
Recycled aggregate specimen & CRCAC & RRCAC & RRCAB \\
\hline
\end{tabular}




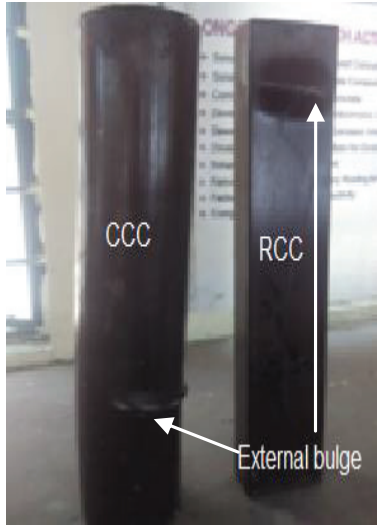

Fig. 9 (a): External buckling in control columns.

\section{CONCLUSIONS}

Based on the experimental work done, the following conclusions were drawn.

Taguchi method used to analysea wide range of values was employed to analyse the compressive and split tensile strengths to obtain the optimum percentage as $40 \%$ of RCA to be replaced for NCA.

It is observed that as per ASTM C1202, the chloride penetration rate is moderate for $40 \%$ RCA in concrete for all grades of concrete.

The correlation expression developed between compressive strength and percentage replacement of recycled

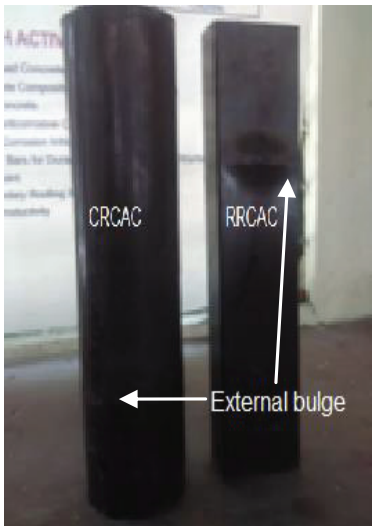

Fig. 9 (b): External buckling in RCA concrete-filled columns.

aggregate in concrete and correlation expression exhibits a remarkable correlation between the chosen parameters.

RCA filled circular columns exhibit higher load-carrying capacity than rectangular sections in both normal and recycled aggregate concrete in filled column.

In the case of beams, the load-carrying capacity of RCA filled beams increased upto $3.62 \%$ and can be used in construction sites.

Use of recycled coarse aggregate in the concrete mixture is found to have sufficient strength properties close to that of natural coarse aggregate. This would enable many construction companies and developers to effectively use

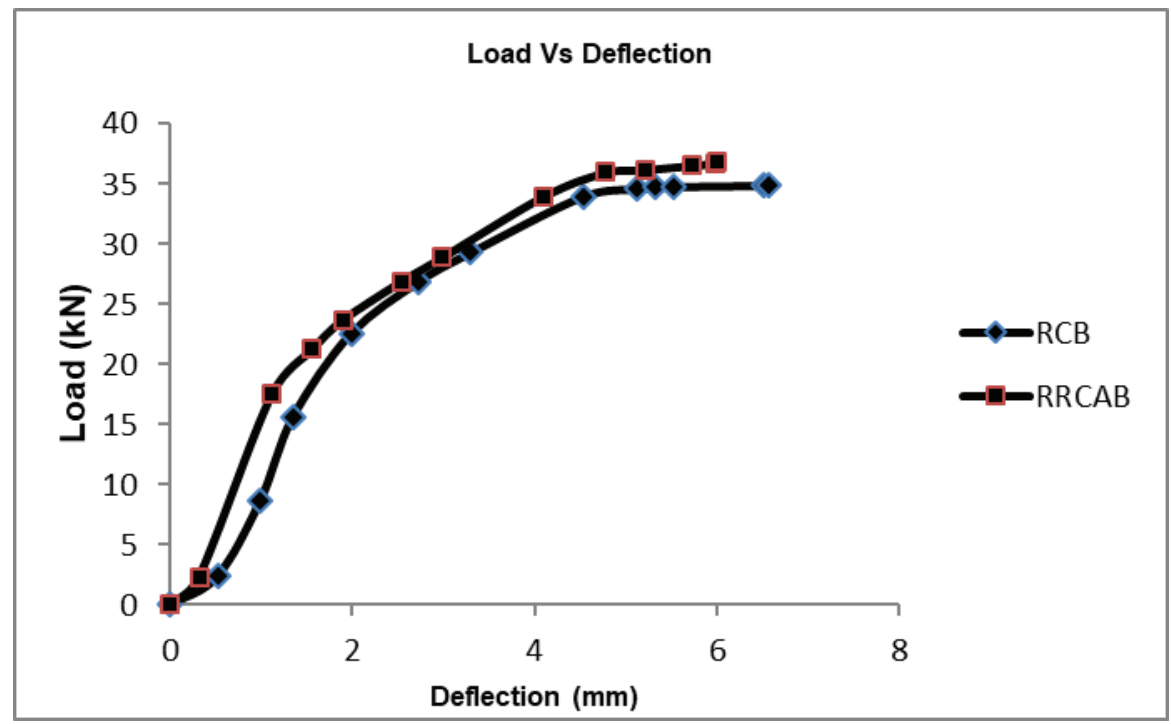

Fig. 10: Load vs deflection curve for beams. 


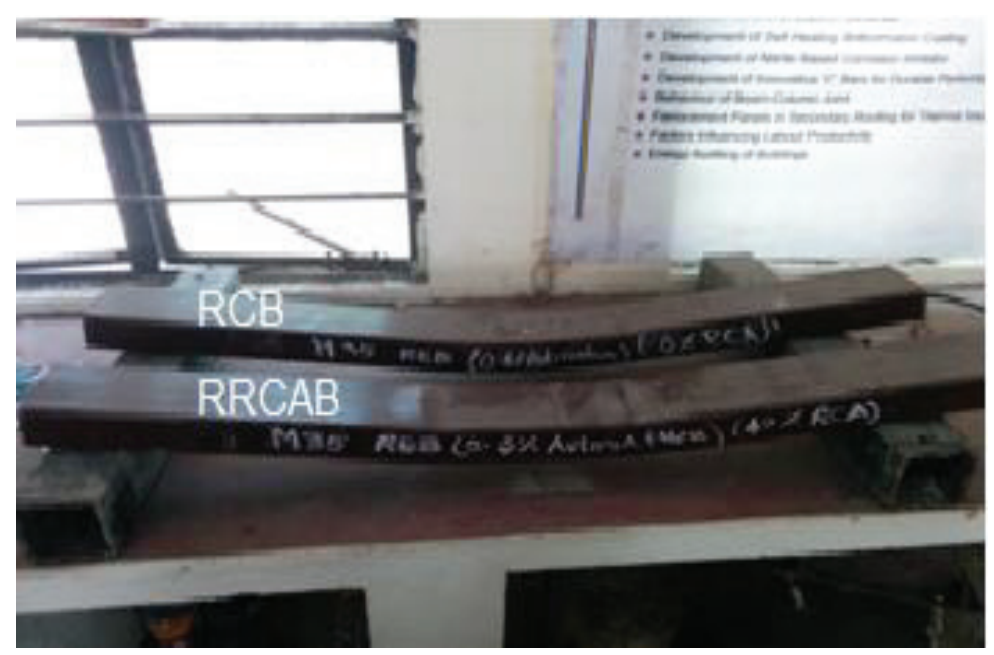

Fig. 11: Failure pattern of beams.

the construction and demolition concrete waste thereby reducing itsimpact as landfills and provide an eco-friendly and sustainable environment.

\section{REFERENCES}

Alexandre Bogas J. and J. de Brito, J. 2014. Long-term behaviour of concrete produced with recycled lightweight expanded clay aggregate concrete. Construction and Building Materials, 65: 470.

Chakradhara, Rao, Bhattacharyya, S.K. and Barai, S.V. 2011. Influence of field recycled coarse aggregate on properties of concrete. Materials and Structures, 44: 205.

Gajalakshmi, P., Jane Helena, H. and Srinivasa Raghavan, R. 2011. Experimental investigation on the Behaviour of concrete-filled steel columns. Asian Journal of Civil Engineering, 2: 691.

Ganesan, 2011. Experiments using Taguchi's Approach. Research Methodology for Engineers. MJP Publishers.

Ganesh, S. and Gajalakshmi, P. 2014. Recycled aggregate concrete for structural applications: A Review. International Journal of Earth Sciences and Engineering, 7: 959.

Kazuhisa, Yoda and Akira,Shintani 2014. Building application of recycled aggregate concrete for upper-ground structural elements. Journal of Construction and Building Materials, 67: 379.

Kou, S.C. and Poon, C.S. 2012.Enhancing the durability properties of concrete prepared with coarse recycled aggregate.Construction and Building Materials, 35: 69.

Matias, D., de Brito, J., Rosa, A. and Pedro, D. 2013. Mechanical properties of concrete produced with recycled coarse aggregates-influence of the use of superplasticizers. Constr. Build. Mater., 44: 101.

Montgomery, D. C., and Peck, E. A. 2015. "Introduction to linear regression analysis". 5th Edn., Wiley, New York.

Taguchi G. 1986. Orthogonal Arrays and Linear Graphs. American Supplier Institute, Inc; Dearborn, MI.

Tiwari, Akansha 2015. Recycled concrete aggregate. International Research Journal of Engineering and Technology, 02: 2395.

Vieira, T., Alves, A., Brito, J., de Correia, J.R. and Silva, R.V. 2016. Durability-related performance of concrete containing fine recycled aggregates from crushed bricks and sanitary ware. Mater. Des., 90: 767.

Vivian, W., Tam, Y., Wang Zhi-Bin and Zhong Tao, 2014. Behaviour of recycled aggregate concretefilled stainless steel stub columns. Materials and Structures, 47: 293.

Wagih, A.M., El-Karmoty, H.Z., Ebid, M. and Okba, S.H. 2013. Recycled construction and demolition concrete waste as aggregate for structural concrete. Housing and Building National Research Center, 9(3): 193-200.

Wang,Yuyin, Chen,Jie and Geng, Yue 2015. Testing and analysis of axially loaded normal-strength recycled aggregate concrete filled steel tubular stub columns. Eng. Struct.,86: 192.

Yang, Youfu and Han,Linhai 2006. Compressive and flexural behaviour of recycled aggregate concrete filled steel tubes (RACFST) under shortterm loadings. Steel Compos. Struct.,6: 257.

Yang,Youfu and Ma, Guoliang 2013. Experimental behaviour of recycled aggregate concrete filled stainless steel tube stub columns and beams. Thin Walled Struct., 66: 62. 